\title{
Acid-base logarithmic diagrams with computer algebra systems
}

\author{
Alberto Gambi ${ }^{1} \cdot$ Rosanna Toniolo $^{2}$
}

Received: 22 March 2016/ Accepted: 19 May 2016/Published online: 1 June 2016

(C) Springer International Publishing Switzerland 2016

\begin{abstract}
The $\mathrm{pH}$ of any polyprotic weak and strong acid (or base) can be calculated employing the logarithmic concentration diagram. The aim of this text is to introduce a joint approach of algebraic, as used in textbook, and graphical method. The logarithmic diagrams provide an easy insight into the acid-base systems. The mathematical complexities are overtaken using a Computer Algebra System program, which is also exploited to draw the diagrams. Examples of the use of the program are given together with the code employed.
\end{abstract}

Keywords Acid-base equilibria · Logarithmic diagrams . Computer algebra $\cdot$ Titration curve $\cdot$ Program code

\section{Introduction}

Acid-base calculations can be carried out with two methods: the algebraic approach that is taught in most Analytical and General Chemistry courses and a graphical estimate to obtain a useful answer with a minimum effort.

In the first method, the quantitative treatment required to derive the equations provides a clearer view of the equilibria involved and can be used as a model to obtain generalized

Electronic supplementary material The online version of this article (doi:10.1007/s40828-016-0029-1) contains supplementary material, which is available to authorized users.

Alberto Gambi

alberto.gambi@uniud.it

1 Università di Udine, DPIA, Via Cotonificio, 108, 33100 Udine, Italy

2 Università di Udine, DI4A, Via Cotonificio, 108, 33100 Udine, Italy equilibria. The alternate graphic method [1, 2], although lacking precision, affords a clearer view of the relationships between the various species related to a given acid-base system. The graphs, related to the definitions of $\mathrm{pH}$ and $\mathrm{pOH}$, report the $\log [S]$ vs. $\mathrm{pH}$, where $[S]$ is the concentration of each species present at equilibrium. They present the interrelations between the logarithm of all equilibrium concentrations of the species and the $\mathrm{pH}$ value of the solution.

In this article, a new approach using the so-called Computer Algebra System (CAS) is presented. In the same way that Personal Computer (PC) or Notebook has actually removed logarithm tables from classroom, it is useful to introduce into laboratory and classroom the CAS as a calculation tool. Students' understanding of general principles and scientific theories is encouraged and the overwhelming calculations can be carried out with great precision and in few seconds by the computer.

In addition, the possibility to display immediately the graphs of all the related species in the solution over the entire $\mathrm{pH}$ range, facilitates the rendering of the problem. The mathematical nature of this approach constitutes itself a way to computer implementation.

This text is organized as follows: we begin in Sec. 2 by presenting the computer program which will be employed for the calculations. In Sec. 3, some mathematical details for the calculations concerning the acid-base equilibria are reported. The logarithmic diagram for a biprotic acid is then discussed in Sec. 4 together with the titration curve and the program code implemented to get the graphs. Next, in Sec. 5, we report another example of diagram which deals with the $\mathrm{pH}$ of a pure acid in water. Section 6 contains some concluding remarks.

The general formulas, which are mandatory for programming purpose, were obtained after the presentation of simpler cases so that the student can understand the extension of the specific example to the general one. 
Throughout the text the following approximations will be active: the hydrogen and hydroxide ions are indicated with $\mathrm{H}^{+}$and $\mathrm{OH}^{-}$, where it is understood that they are hydrated ions. The activities of the various species are assumed to be equal to the molar concentration.

\section{The Maxima program}

In 1984, during the 188th national meeting of the American Chemical Society, the ACS Division of Computer in Chemistry held a symposium on Symbolic Algebraic Manipulation in Scientific Computation. At that time, the chemistry community was the most recent larger scientific group to recognize the convenience of using Computer Algebra Systems [3].

Since then, computer algebra became a commonplace both in chemical research and education with several applications which have been described in the chemistry literature [4-6]. This approach to the solution of chemistry problems is also present in many modern Chemistry textbooks (see for example Ref. [7]).

The use of advanced mathematical methods has become increasingly significant in modern chemistry. Their efficient use requires apart from underlying theoretical knowledge of the chemical problem also familiarity with relevant software packages. The aim of this article is to provide the essential commands to get significant results and constitute the basis for further developments.

The freeware application "wxMaxima" for symbolic and numerical calculations [8] will be used throughout. This program invokes the public-domain graphics package Gnuplot [9] for visualizing computation results. The graphs produced this way can also be readily customized using Gnuplot in a stand-alone fashion.

wxMaxima is a system, consisting of the core code package Maxima [10] which does the actual computations and an interactive user interface based on the so called x-widgets.

Maxima belongs to a category of mathematics software known as computer algebra systems. Maxima and wxMaxima are freeware, easy to install and available on many operating systems including Windows, Linux and Mac OS X. Before downloading the whole application from a web site, the student/teacher/lecturer can try the powerful Maxima computer algebra system online [11] for ad hoc calculations including the examples reported here.

\section{The Math behind the acid-base equilibria}

All the forthcoming equations are based on the acid-base theory of Brønsted and Lowry, according to whom acids are proton donors and bases are proton acceptors.
We start considering a monoprotic weak acid HA with concentration $C_{a}$ which undergoes the dissociation equilibrium

$\mathrm{HA} \rightleftharpoons \mathrm{H}^{+}+\mathrm{A}^{-}$

with equilibrium constant

$K_{a}=\frac{\left[\mathrm{H}^{+}\right]\left[\mathrm{A}^{-}\right]}{[\mathrm{HA}]}$

From water autoprotolysis we have in addition:

$\mathrm{H}_{2} \mathrm{O} \rightleftharpoons \mathrm{H}^{+}+\mathrm{OH}^{-}$

with equilibrium constant

$K_{w}=\left[\mathrm{H}^{+}\right]\left[\mathrm{OH}^{-}\right]$

The amount balance equation relates the nominal concentration of the acid in terms of its two conjugate forms

$C_{a}=[\mathrm{HA}]+\left[\mathrm{A}^{-}\right]$

and dividing Eq. 5 by $C_{a}$ we get

$1=\frac{[\mathrm{HA}]}{C_{a}}+\frac{\left[\mathrm{A}^{-}\right]}{C_{a}}=\alpha_{0}+\alpha_{1}$

where $\alpha_{0}$ and $\alpha_{1}$ represent the degree of undissociated and dissociated acid, respectively. From Eqs. 2 and 5, we get

$\alpha_{0}=\frac{[\mathrm{HA}]}{[\mathrm{HA}]+\left[\mathrm{A}^{-}\right]}=\frac{\left[\mathrm{H}^{+}\right]}{K_{a}+\left[\mathrm{H}^{+}\right]}$

and

$\alpha_{1}=\frac{\left[\mathrm{A}^{-}\right]}{[\mathrm{HA}]+\left[\mathrm{A}^{-}\right]}=\frac{K_{a}}{K_{a}+\left[\mathrm{H}^{+}\right]}=\frac{K_{a} \alpha_{0}}{\left[\mathrm{H}^{+}\right]}$

From the charge balance

$\left[\mathrm{H}^{+}\right]-\left[\mathrm{OH}^{-}\right]-\left[\mathrm{A}^{-}\right]=0$

and Eqs. 4 and 8 we have

$\left[\mathrm{H}^{+}\right]-\frac{K_{w}}{\left[\mathrm{H}^{+}\right]}-C_{a} \alpha_{1}=\left[\mathrm{H}^{+}\right]-\frac{K_{w}}{\left[\mathrm{H}^{+}\right]}-\frac{C_{a} K_{a}}{K_{a}+\left[\mathrm{H}^{+}\right]}=0$

This equation is cubic in $\left[\mathrm{H}^{+}\right]$and in standard polynomial form it becomes

$$
\left[\mathrm{H}^{+}\right]^{3}+K_{a}\left[\mathrm{H}^{+}\right]^{2}-\left(K_{w}+C_{a} K_{a}\right)\left[\mathrm{H}^{+}\right]-K_{w} K_{a}=0
$$

In many practical applications, we can make approximations that eliminate the need to solve the cubic equations. The students will appreciate that using the program presented later the problem of approximations is removed.

If we consider now a diprotic acid $\mathrm{H}_{2} \mathrm{~A}$, the following equilibria and equations should be considered: 
$\mathrm{H}_{2} \mathrm{~A} \rightleftharpoons \mathrm{H}^{+}+\mathrm{HA}^{-} \quad ; \quad \mathrm{HA}^{-} \rightleftharpoons \mathrm{H}^{+}+\mathrm{A}^{2-}$

$K_{a_{1}}=\frac{\left[\mathrm{H}^{+}\right]\left[\mathrm{HA}^{-}\right]}{\left[\mathrm{H}_{2} \mathrm{~A}\right]} \quad ; \quad K_{a_{2}}=\frac{\left[\mathrm{H}^{+}\right]\left[\mathrm{A}^{2-}\right]}{[\mathrm{HA}-]}$

and from the amount balance

$C_{a}=\left[\mathrm{H}_{2} \mathrm{~A}\right]+\left[\mathrm{HA}^{-}\right]+\left[\mathrm{A}^{2-}\right]$

the following ionization fractions are obtained

$\alpha_{0}=\frac{\left[\mathrm{H}_{2} \mathrm{~A}\right]}{C_{a}}=\frac{\left[\mathrm{H}^{+}\right]^{2}}{\left[\mathrm{H}^{+}\right]^{2}+\left[\mathrm{H}^{+}\right] K_{a_{1}}+K_{a_{1}} K_{a_{2}}}$

$\alpha_{1}=\frac{\left[\mathrm{HA}^{-}\right]}{C_{a}}=\frac{\left[\mathrm{H}^{+}\right] K_{a_{1}}}{\left[\mathrm{H}^{+}\right]^{2}+\left[\mathrm{H}^{+}\right] K_{a_{1}}+K_{a_{1}} K_{a_{2}}}=\frac{K_{a_{1}} \alpha_{0}}{\left[\mathrm{H}^{+}\right]}$

$\alpha_{2}=\frac{\left[\mathrm{A}^{2-}\right]}{C_{a}}=\frac{K_{a_{1}} K_{a_{2}}}{\left[\mathrm{H}^{+}\right]^{2}+\left[\mathrm{H}^{+}\right] K_{a_{1}}+K_{a_{1}} K_{a_{2}}}=\frac{K_{a_{1}} K_{a_{2}} \alpha_{0}}{\left[\mathrm{H}^{+}\right]^{2}}$

The charge balance is now

$\left[\mathrm{H}^{+}\right]-\left[\mathrm{OH}^{-}\right]-\left[\mathrm{HA}^{-}\right]-2\left[\mathrm{~A}^{2-}\right]=0$

$\left[\mathrm{H}^{+}\right]-\frac{K_{w}}{\left[\mathrm{H}^{+}\right]}-C_{a} \alpha_{1}-2 C_{a} \alpha_{2}=0$

leading to a fourth-order polynomial equation

$$
\begin{aligned}
{\left[\mathrm{H}^{+}\right]^{4} } & +K_{a_{1}}\left[\mathrm{H}^{+}\right]^{3}-\left(C_{a} K_{a_{1}}-K_{a_{1}} K_{a_{2}}+K_{w}\right)\left[\mathrm{H}^{+}\right]^{2} \\
& -\left(K_{w}+2 C_{a} K_{a_{2}}\right) K_{a_{1}}\left[\mathrm{H}^{+}\right]-K_{a_{1}} K_{a_{2}} K_{w}=0
\end{aligned}
$$

These results can be extended to an acid with $n$ dissociable hydrogen ions. The following equilibria exist:

$\mathrm{H}_{\mathrm{n}-\mathrm{i}+1} \mathrm{~A}^{(\mathrm{i}-1)-} \rightleftharpoons \mathrm{H}^{+}+\mathrm{H}_{\mathrm{n}-\mathrm{i}} \mathrm{A}^{\mathrm{i}-} \quad \mathrm{i}=1, \ldots, \mathrm{n}$

with equilibrium constants $[12,13]$ :

$K_{a_{\mathrm{i}}}=\frac{\left[\mathrm{H}^{+}\right]\left[\mathrm{H}_{\mathrm{n}-\mathrm{i}} \mathrm{A}^{\mathrm{i}-}\right]}{\left[\mathrm{H}_{\mathrm{n}-\mathrm{i}+1} \mathrm{~A}^{(\mathrm{i}-1)-}\right]} \quad \mathrm{i}=1, \ldots, \mathrm{n}$

The degree of dissociation or acid ionization fraction [14] in this case is:

$\alpha_{0}=\frac{\left[\mathrm{H}^{+}\right]^{i}}{\left[\mathrm{H}^{+}\right]^{i}+\sum_{k=1}^{i}\left[\mathrm{H}^{+}\right]^{i-k} \prod_{j=1}^{k} K_{a_{j}}} \quad i=1, \ldots, n$

$\alpha_{i}=\frac{\prod_{j=1}^{i} K_{a_{j}} \alpha_{0}}{\left[\mathrm{H}^{+}\right]^{i}} \quad i=1, \ldots, n$

For programming purpose it is convenient to merge Eqs. 14 and 15 into

$$
\alpha_{i}=\frac{\left[\mathrm{H}^{+}\right]^{n-i} \prod_{j=1}^{i} K_{a_{j}}}{\left[\mathrm{H}^{+}\right]^{n}+\sum_{k=1}^{n}\left[\mathrm{H}^{+}\right]^{n-k} \prod_{j=1}^{k} K_{a_{j}}} \quad i=0,1, \ldots, n
$$

The amount balance becomes:

$C_{a}=\sum_{\mathrm{i}=0}^{\mathrm{n}}\left[\mathrm{H}_{\mathrm{n}-\mathrm{i}} \mathrm{A}^{\mathrm{i}-}\right]$

with, respectively, the following equilibrium concentration of the species

$$
\left[\mathrm{H}_{\mathrm{n}-\mathrm{i}} \mathrm{A}^{\mathrm{i}-}\right]=C_{a} \alpha_{\mathrm{i}} \quad \mathrm{i}=0,1, \ldots, \mathrm{n}
$$

and charge balance

$$
\left[\mathrm{H}^{+}\right]-\frac{K_{\mathrm{w}}}{\left[\mathrm{H}^{+}\right]}-\sum_{i=1}^{n} i C_{a} \alpha_{i}=0
$$

These equations lead to a polynomial expression of $(n+2)$ th order with respect to the hydrogen ions concentration.

Similar equations can be derived for the bases:

$$
\mathrm{BH}_{\mathrm{i}-1}^{(\mathrm{i}-1)+}+\mathrm{H}_{2} \mathrm{O} \rightleftharpoons \mathrm{OH}^{-}+\mathrm{BH}_{\mathrm{i}}^{\mathrm{i}+} \quad \mathrm{i}=1, \ldots, \mathrm{n}
$$

with equilibrium constants:

$K_{b_{\mathrm{i}}}=\frac{\left[\mathrm{OH}^{-}\right]\left[\mathrm{BH}_{\mathrm{i}}^{\mathrm{i}+}\right]}{\left[\mathrm{BH}_{\mathrm{i}-1}^{(\mathrm{i}-1)+}\right]} \quad \mathrm{i}=1, \ldots, \mathrm{n}$

The equilibrium concentration of each species in this case is:

$$
\left[\mathrm{BH}_{\mathrm{i}}^{\mathrm{i}+}\right]=C_{b} \beta_{\mathrm{i}} \quad \mathrm{i}=0,1, \ldots, \mathrm{n}
$$

where $C_{b}$ is the nominal concentration of the base and $\beta_{i}$ are the base ionization fractions, obtained from Eq. 16 by replacing $\left[\mathrm{H}^{+}\right]$with $\left[\mathrm{OH}^{-}\right]$and $K_{a_{j}}$ with $K_{b_{j}}$.

$$
\beta_{i}=\frac{\left[\mathrm{OH}^{-}\right]^{n-i} \prod_{j=1}^{i} K_{b_{j}}}{\left[\mathrm{OH}^{-}\right]^{n}+\sum_{k=1}^{n}\left[\mathrm{OH}^{-}\right]^{n-k} \prod_{j=1}^{k} K_{b_{j}}} \quad i=0,1, \ldots, n
$$

\section{The logarithmic diagram}

In Eq. 17, the equilibrium concentrations of the species depend on $[\mathrm{H}+]$ and, therefore, on $\mathrm{pH}$. Their logarithm will be plotted in the graph as depicted in Fig. 1.

Equation 18 should be used to compute the $\mathrm{pH}$ of the solution of the $n$-protic acid. This equation can be modified to include the $\mathrm{pH}$ calculation of the salt solutions $\mathrm{M}_{\mathrm{r}} \mathrm{H}_{\mathrm{n}-\mathrm{r}} \mathrm{A}$ with $r=0,1, \ldots, n$ obtained from the polyprotic acid, $H_{n} A$ after reaction with a simple monoacidic base, $\mathrm{MOH}$. In the case of a biprotic acid, the following salt dissociations should be taken into account if one or both the hydrogens have been replaced by $M$ 


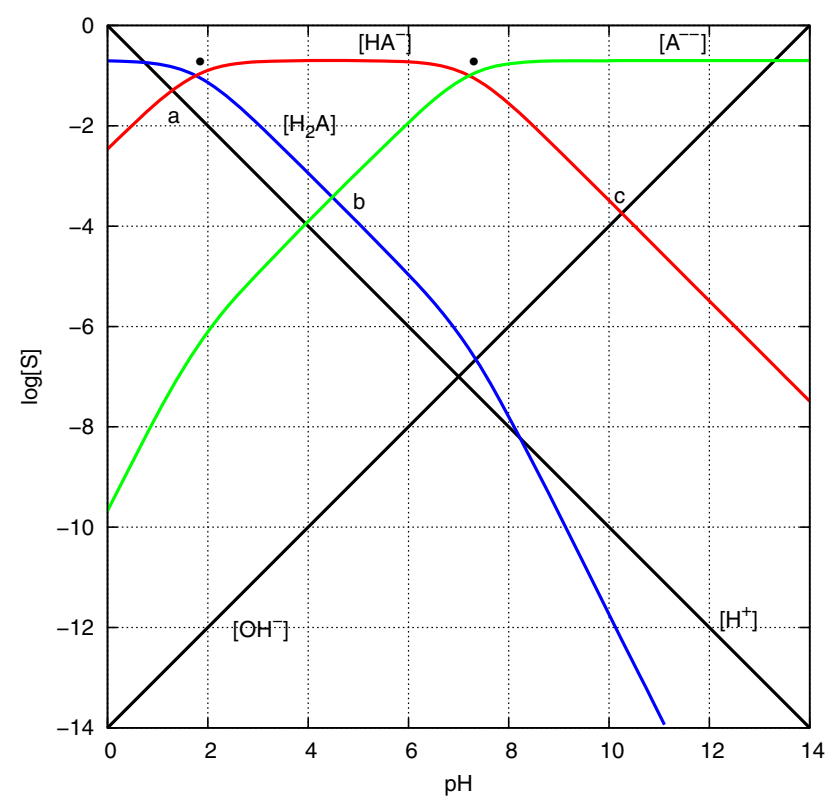

Fig. 1 Logarithmic diagram for a biprotic acid, $\mathrm{H}_{2} \mathrm{~A}$, in water. The diagram includes the autoionization of water. The numerical values of system points (filled circle) and of the other relevant information ( $\mathrm{a}, \mathrm{b}$, c) are summarized in Table 1

Table 1 Summary of data shown in Figs. 1 and 2 with the indication of the relevant points (see text for details)

\begin{tabular}{lllll}
\hline Input & Output & & \\
\hline$K_{a_{1}}$ & $1.74 \times 10^{-2} p K_{a_{1}}=1.76(\bullet)$ & $\mathrm{pH}\left(\mathrm{H}_{2} \mathrm{~A}\right)$ & 1.29 & (a) \\
$K_{a_{2}}$ & $6.17 \times 10^{-8} p K_{a_{2}}=7.21(\bullet)$ & $\mathrm{pH}(\mathrm{MHA})$ & 4.50 & (b) \\
$C_{a}$ & $0.20 \mathrm{~mol} / \mathrm{L}$ & $\mathrm{pH}\left(\mathrm{M}_{2} \mathrm{~A}\right)$ & 10.26 & $(\mathrm{c})$ \\
$C_{b}$ & $0.20 \mathrm{~mol} / \mathrm{L}$ & $\mathrm{pH}(\tau=1)$ & 4.52 & \\
& & $\mathrm{pH}(\tau=2)$ & 10.02 & \\
\hline
\end{tabular}

$\mathrm{MHA} \longrightarrow \mathrm{M}^{+}+\mathrm{HA}^{-}$

$\mathrm{M}_{2} \mathrm{~A} \longrightarrow 2 \mathrm{M}^{+}+\mathrm{A}^{2-}$

and in general for the $n$-protic acid

$\mathrm{M}_{\mathrm{r}} \mathrm{H}_{\mathrm{n}-\mathrm{r}} \mathrm{A} \longrightarrow \mathrm{rM}^{+}+\mathrm{H}_{\mathrm{n}-\mathrm{r}} \mathrm{A}^{\mathrm{r}-} \quad \mathrm{r}=0,1, \ldots, \mathrm{n}$

Therefore, the charge balance should include the concentration of the $\mathrm{M}^{+}$ions

$$
\left[\mathrm{H}^{+}\right]+r\left[\mathrm{M}^{+}\right]-\frac{K_{w}}{\left[\mathrm{H}^{+}\right]}-\sum_{i=1}^{n} i C_{a} \alpha_{i}=0 \quad r=0,1, \ldots, n
$$

In this case, $C_{a}$ represents the salt concentration.

Notice that Eq. 20 in regular polynomial form is a

computer program. Scanning the $n+2$ solutions for a positive value, will give the exact $\mathrm{pH}$ of the solution.

The student is encouraged to interact with the CASprocedure and not to consider the program a "black-box" with knobs and switches.
For example, the behavior of biprotic acids can be easily described by diagrams such as that reported in Fig. 1, computed using the input data reported in Table 1. It shows the logarithmic dependence on $\mathrm{pH}$ of the equilibrium concentrations of the species provided by a diprotic acid $\mathrm{H}_{2} \mathrm{~A}\left(\mathrm{H}_{2} \mathrm{~A}, \mathrm{HA}^{-}\right.$and $\left.\mathrm{A}^{2-}\right)$ at an analytical concentration $\left(C_{a}\right)$ of $0.2 \mathrm{~mol} / \mathrm{L}$, together with those of $\mathrm{H}^{+}$and $\mathrm{OH}^{-}$. This diagram is based on the amount balance and the relevant acid dissociation constants.

The log of equilibrium concentration of the fully protonated form $\mathrm{H}_{2} \mathrm{~A}$ approximates the analytical concentration at $\mathrm{pH}<p K_{a_{1}}(1.76)$, while it decreases with a slope -1 at $\mathrm{pH}$ higher than $p K_{a_{1}}$ and lower than $p K_{a_{2}}$ (7.21) owing to the release of one proton occurring in this range to give $\mathrm{H}^{-}$. At $\mathrm{pH}>p K_{a_{2}}$ a decrease with a slope -2 becomes apparent because two protons are released in this range to give $\mathrm{A}^{2-}$. Concomitantly, the equilibrium concentration of the conjugated base $\mathrm{HA}^{-}$becomes almost coincident with $C_{a}$ in the range $p K_{a_{1}}<\mathrm{pH}<p K_{a_{2}}$ while the logarithm of its concentration decreases at both $\mathrm{pH}<p K_{a_{1}}$ (with a slope +1 , due to the uptake of one proton, to give the conjugate acid $\mathrm{H}_{2} \mathrm{~A}$ ) and $\mathrm{pH}>p K_{a_{2}}$ (with slope -1 ), where $\mathrm{HA}^{-}$releases one proton, to give the conjugate base $\mathrm{A}^{2-}$. Finally, $\mathrm{A}^{2-}$ base attains an equilibrium concentration corresponding to $C_{a}$ only at $\mathrm{pH}>p K_{a_{2}}$, where $\mathrm{H}_{2} \mathrm{~A}$ undergoes a two-proton release, while the logarithm of its concentration decrease with a slope +1 in the range $p K_{a_{2}}>\mathrm{pH}>p K_{a_{1}}$ (where $\mathrm{A}^{2-}$ undergoes a one-proton uptake to give HA- and with a slope +2 at $\mathrm{pH}<p K_{a_{1}}$ because in this range $\mathrm{A}^{2-}$ is subjected to a two proton uptake, to give directly $\mathrm{H}_{2} \mathrm{~A}$. It should be mentioned that the integer value of the positive or negative slope is actually an approximation arising from Eq. 17.

Of course, when slopes change (in coincidence with $\mathrm{pH}=p K_{a_{1}}$ or $p K_{a_{2}}$ ), right lines are connected by bending lines extending about $1 \mathrm{pH}$ unit at both sides. It is worth to underline that points in this type of diagrams characterized by coordinates equal to $\left(p K_{a_{1}} ; \log C_{a}\right)$ and $\left(p K_{a_{2}} ; \log C_{a}\right)$ are usually named "system points". Logarithmic diagrams of this type enable not only an effective view of the equilibrium concentration of all species at any $\mathrm{pH}$, but allow the $\mathrm{pH}$ for $\mathrm{H}_{2} \mathrm{~A}, \mathrm{HA}^{-}$or $\mathrm{A}^{2-}$ solutions at analytical concentration $C_{a}$ to be located.

\section{Titration curves}

Logarithmic plots of this type are also useful tools providing detailed information on titration curves of either acid species with strong bases or conjugated basic species with strong acids. For analytical applications, explicit expressions and the shape of the titration curve can provide insight into the conditions needed for a clear endpoint. Such expressions also allow to draw titration curves and 
obtain the amounts of the titratable components. In addition, the explicit expression for the titration curve allows equilibrium constants to be extracted from it.

Generally, acid-base titration diagrams show the $\mathrm{pH}$ of the solution as a function of the volume of added titrator. It is convenient to combine the concentration of the acid $\left(C_{a}\right)$ and its volume $\left(V_{a}\right)$, the concentration of the base $\left(C_{b}\right)$ and its volume $\left(V_{b}\right)$ and the total volume of the solution $\left(V_{a}+V_{b}\right)$ into a dimensionless parameter, $\tau$, that indicates the degree of completion of the titration. Taking into account the titration of a strong acid (HA) with a strong base $(\mathrm{MOH})$, we have from the charge balance

$$
\left[\mathrm{H}^{+}\right]+\left[\mathrm{M}^{+}\right]=\left[\mathrm{A}^{-}\right]+\left[\mathrm{OH}^{-}\right]
$$

From the amount balance, considering the total volume of the solution after the adding of the titrator, we get:

$$
\left[\mathrm{A}^{-}\right]=\frac{C_{a} V_{a}}{V_{a}+V_{b}} \quad \text { and } \quad\left[\mathrm{M}^{+}\right]=\frac{C_{b} V_{b}}{V_{a}+V_{b}}
$$

Introducing these values in Eq. 21 will give:

$\frac{V_{a}}{V_{b}}=\frac{C_{a}-\left[\mathrm{H}^{+}\right]+\left[\mathrm{OH}^{-}\right]}{C_{b}+\left[\mathrm{H}^{+}\right]+\left[\mathrm{OH}^{-}\right]}$

Therefore, the dimensionless parameter, which represents the moles of added titrator (base) divided by the moles of the titrated (acid), will be

$$
\tau_{a b}=\frac{C_{b} V_{b}}{C_{a} V_{a}}=\frac{1-\frac{\left[\mathrm{H}^{+}\right]-\left[\mathrm{OH}^{-}\right]}{C_{a}}}{1+\frac{\left[\mathrm{H}^{+}\right]-\left[\mathrm{OH}^{-}\right]}{C_{b}}}
$$

If we consider a weak monoprotic acid, HA, now the amount balance must include the undissociated acid,

$$
[\mathrm{HA}]+\left[\mathrm{A}^{-}\right]=\frac{C_{a} V_{a}}{V_{a}+V_{b}}
$$

and introducing the degree of dissociation of the acid, $\alpha_{1}$ (Eq. 8), the explicit expression for the degree of titration becomes

$$
\tau_{a b}=\frac{\alpha_{1}-\frac{[\mathrm{H}+]-[\mathrm{OH}-]}{C_{a}}}{1+\frac{\left[\mathrm{H}^{+}\right]-\left[\mathrm{OH}^{-}\right]}{C_{b}}}
$$

Although it is not advisable to titrate a weak acid with a weak base, to have a general formalism, we consider the employment of a weak base titrator. Now the charge balance is

$$
\left[\mathrm{H}^{+}\right]+\left[\mathrm{BH}^{+}\right]=\left[\mathrm{A}^{-}\right]+\left[\mathrm{OH}^{-}\right]
$$

and the amount balance, in addition to Eq. 22, should consider the following terms
$[\mathrm{B}]+\left[\mathrm{BH}^{+}\right]=\frac{C_{b} V_{b}}{V_{a}+V_{b}}$

Introducing the degree of dissociation of the base, $\beta_{1}$ (from Eq. 19 with $i=1$ ), the degree of titration will be

$\tau_{a b}=\frac{\alpha_{1}-\frac{\left[\mathrm{H}^{+}\right]-\left[\mathrm{OH}^{-}\right]}{C_{a}}}{\beta_{1}+\frac{\left[\mathrm{H}^{+}\right]-\left[\mathrm{OH}^{-}\right]}{C_{b}}}$

These equations can be extended to polyprotic acids and bases replacing $\left[\mathrm{OH}^{-}\right]=K_{w} /\left[\mathrm{H}^{+}\right]$from the water autoprotolysis equilibrium constant, Eq. 4, and introducing the following acid and base dissociation functions:

$$
F_{a}=\sum_{i=1}^{n} i \alpha_{i} \quad ; \quad F_{b}=\sum_{i=1}^{n} i \beta_{i}
$$

where in case of strong acid or base either $F_{a}$ or $F_{b}$ should be replaced by 1 (i.e., $100 \%$ dissociation). Therefore, the general formula of the degree of titration can be cast as [15]

$$
\tau_{a b}=\frac{F_{a}-\frac{\left[H^{+}\right]-\left[K_{w} / \mathrm{H}^{+}\right]}{C_{a}}}{F_{b}+\frac{\left[\mathrm{H}^{+}\right]-\left[K_{w} / \mathrm{H}^{+}\right]}{C_{b}}}
$$

Actually Eq. 24 represents the dimensionless parameter $\tau$ in function of the hydrogen ionic concentration.

To illustrate that titration curves may be significantly different for the case that an acid is titrated and the case where the corresponding base is titrated, the titration of the $\mathrm{M}_{\mathrm{n}} \mathrm{A}$ with a strong monoprotic acid, $\mathrm{HX}$, is also taken into account.

The dimensionless parameter $\tau_{b a}$ will be:

$\tau_{b a}=\frac{1}{\tau_{a b}}=\frac{F_{b}+\frac{\left[\mathrm{H}^{+}\right]-\left[\mathrm{OH}^{-}\right]}{C_{b}}}{1-\frac{\left[\mathrm{H}^{+}\right]-\left[\mathrm{OH}^{-}\right]}{C_{a}}}$

and the corresponding base dissociation function is $F_{b}$, which for the conjugate bases of the polyprotic acid is:

$$
F_{b}=\sum_{i=0}^{n-1}(n-i) \alpha_{i}
$$

However, in both cases it is preferred to plot a graph where the $\mathrm{pH}$ is the ordinate and $\tau$ the abscissa, as shown in Fig. 2.

Thus, Fig. 2 reports titration curves for $\mathrm{H}_{2} \mathrm{~A}$ with a strong base (blue line) and $\mathrm{A}^{2-}$ with a strong acid (red line), whose acid-base equilibria are regulated as depicted in Fig. 1. These curves are constructed by plotting the solution $\mathrm{pH}$ against the titrated fraction $\tau$ (see Eq. 24) which is simply the number of moles of the added titrant 


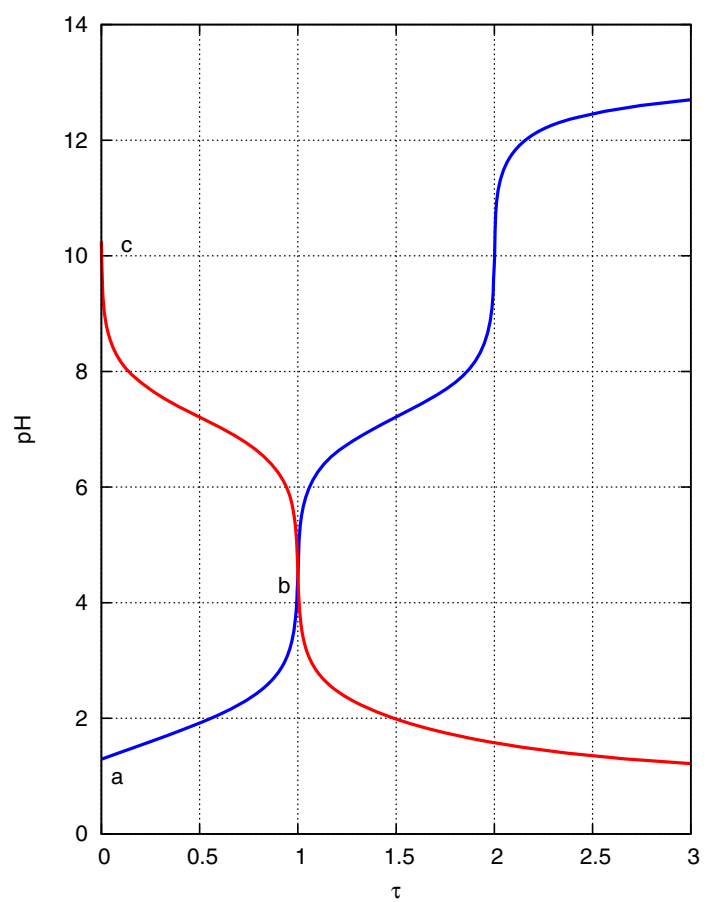

Fig. 2 Blue line titration curves for the acid $\mathrm{H}_{2} \mathrm{~A}$ employing a strong base $\mathrm{MOH}$ with concentration $C_{b}$. Red line titration of the $\mathrm{M}_{2} \mathrm{~A}$ salt with a strong monoprotic acid, HX. See Table 1 for the numerical values and Fig. 1

per mole of the titrated present in solution. The use of $\tau$ allows normalized titration curves to be obtained, in which the amount of titrant required to reach the equivalence point is independent of both strength and concentration of the titrated species. As shown in Fig. 2, the titration curve for the acid $\mathrm{H}_{2} \mathrm{~A}\left(C_{a}\right)$ with the strong base $\mathrm{MOH}\left(C_{b}\right)$ exhibits two equivalence points at the pHs corresponding to $\tau=1$ and $\tau=2$. Although the dilution can be neglected in many cases when concentrated titrants are employed, the $\mathrm{pH}$ at the two equivalence points were calculated exactly and the values are reported in Table 1 . The $\mathrm{pH}$ at the first equivalent point $(\tau=1)$ is close to that of a solution of the conjugate base HA- with the initial concentration $C_{a}$ [point (a) in Table 1], while at the second equivalence point, when the dilution of the solution increases, the $\mathrm{pH}$ is now much more far from that of a solution of the diprotic base $\mathrm{A}^{2-}$ once again at the concentration $C_{a}$ [point (a) in Table 1]. As to the titration curve for $\mathrm{A}^{2-}$ (Fig. 2, red line) it shows a single equivalent point (conversion of $\mathrm{A}^{2-}$ to $\mathrm{HA}^{-}$) alone, because the second equivalence point (conversion of $\mathrm{HA}^{-}$ to $\mathrm{H}_{2} \mathrm{~A}$ ) is located at pHs quite close to those reached when an excess of acid titrant is added (or not revealed because of the low basic strength of $\mathrm{HA}^{-}$).

A plot similar to the blue line of Fig. 2 where the abscissa now represents the volume of added base can be obtained also from Eq. 24 if a specific volume of the biprotic acid is assumed. The program code to get this graph is available in Online Resource 1.

\section{The program code}

In the following, there will be a look at some brief examples on the use of wxMaxima to manage the equations displayed above. The main Maxima's web site [10] provides an entire section dedicated to the documentation and tutorials available in many languages. Therefore, only the minimal and straightforward commands required to get the results will be discussed here. These commands can also be checked with the Maxima-online interface [11].

To differentiate the computer instructions from the normal text, the typewriter character fonts have been chosen for them. The first instructions define the logarithm to the base 10 which is not present in Maxima and the number of digits to print to avoid annoying long numbers.

$$
\begin{aligned}
& \text { fpprintprec : } 5 ; \\
& \log 10(\mathrm{x}):=\log (\mathrm{x}) / \log (10.0)
\end{aligned}
$$

To assign a value to a variable, Maxima uses the colon (:), not the equal sign. The equal sign is used for representing equations. To tell Maxima that you have finished your command, press the Shift+Return keys or use the semicolon (;) in the online version, more than one instruction can stay on the same line. The symbol ":=" defines a function. Then the input data, reported in Table 1, are entered:

$$
\begin{aligned}
& \mathrm{n}: 2 ; \mathrm{ca}: 0.2 ; \mathrm{cb}: 0.2 ; \mathrm{kw}: 1.0 \mathrm{e}-14 ; \\
& \text { costa[1]:1.74e-2; costa[2]:6.17e-8; }
\end{aligned}
$$

These data can also be taken interactively from the keyboard. Then $\left[\mathrm{H}^{+}\right]$and $\left[\mathrm{OH}^{-}\right]$are defined as functions of $\mathrm{pH}$.

$$
\begin{aligned}
& \operatorname{concH}(\mathrm{pH}):=\operatorname{float}\left(10^{\wedge}(-\mathrm{pH})\right) ; \\
& \operatorname{concOH}(\mathrm{pH}):=\mathrm{kw} / \mathrm{float}\left(10^{\wedge}(-\mathrm{pH})\right) ;
\end{aligned}
$$

Here are coded Eqs. 16 and 17 as function of index $i$ and $\mathrm{pH}$ :

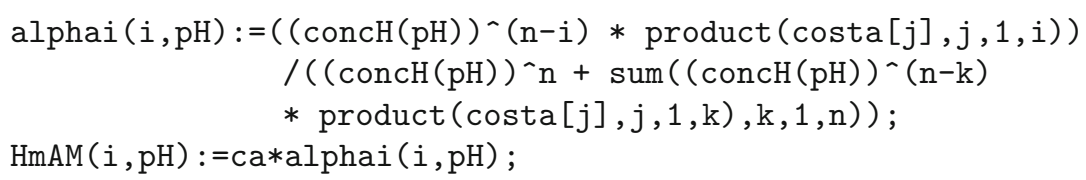


Now all the data required for Fig. 1 can be generated. To plot in the same graph more curves, lists will be created:

fissi: $[\log 10(\operatorname{concH}(\mathrm{pH})), \log 10(\operatorname{concOH}(\mathrm{pH}))]$; anion:makelist $(\log 10(\operatorname{HmAM}(i, p H)), i, 0, n)$;

merged together

$$
\text { grafo: append(fissi, anion); }
$$

and finally drawn: and Eq. 25 will be:

$$
\begin{aligned}
\operatorname{taub}(\mathrm{pH}):= & ((\mathrm{fab}(\mathrm{pH})+\operatorname{concH}(\mathrm{pH})-\operatorname{concOH}(\mathrm{pH})) / \mathrm{ca}) \\
& /(1.0-(\operatorname{concH}(\mathrm{pH})-\operatorname{concOH}(\mathrm{pH})) / \mathrm{cb}) ;
\end{aligned}
$$

These functions can be easily plotted, if $\tau$ is the ordinate and $\mathrm{pH}$ the abscissa. However, it is preferred to have the

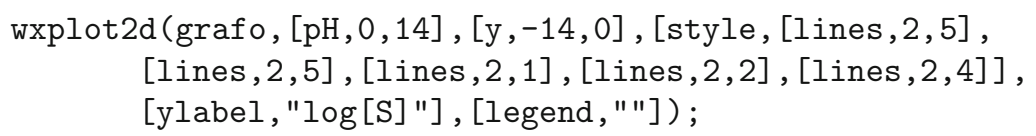

The next steps will set Eq. 23 which can be used in both Eqs. 20 and 24.

$$
\mathrm{fac}(\mathrm{pH}):=\operatorname{sum}(i * c a * a l p h a i(i, p H), i, 1, n) \text {; }
$$

From Eq. 20, the pH of the pure acid $\left(\mathrm{H}_{\mathrm{n}} \mathrm{A}\right)$ and the salts $\left(\mathrm{M}_{\mathrm{r}} \mathrm{H}_{\mathrm{n}-\mathrm{r}} \mathrm{A}\right)$, may be computed and displayed: contrary and, therefore, a small trick should be done. The data points are collected in arrays every $0.1 \mathrm{pH}$ unit to have smooth lines,

for i:0 thru 139 do (xl [i] : tau (i/10),yl[i]:float (i/10), xb[i]: $\operatorname{taub}(i / 10))$;

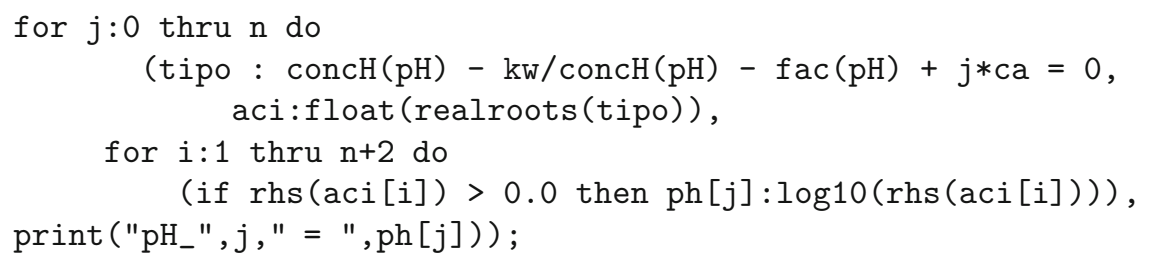

The dimensionless parameter $\tau$ of Eq. 24 is coded as a function of $\mathrm{pH}$ :

$$
\begin{aligned}
\operatorname{tau}(\mathrm{pH}):= & ((\mathrm{fac}(\mathrm{pH})-\operatorname{concH}(\mathrm{pH})+\operatorname{concOH}(\mathrm{pH})) / \mathrm{ca}) \\
& /(1.0+(\operatorname{concH}(\mathrm{pH})-\operatorname{concOH}(\mathrm{pH})) / \mathrm{cb}) ;
\end{aligned}
$$

As the same way above Eq. 26 is coded as:

$f a b(p H):=\operatorname{sum}((n-i) * c b * a l p h a i(i, p H), \quad i, 0, n-1)$;

with the following $\mathrm{pH}$ values, reported in Table 1 , at the equivalence points: the arrays are then transformed into lists:

$$
\begin{aligned}
& \text { myx:makelist (xl[i], i, 0,139); } \\
& \text { myy:makelist (yl[i], i, 0,139); } \\
& \text { myb:makelist (xb [i] ,i , 0,139); }
\end{aligned}
$$

which can now be drawn as points on the graph depicted in Fig. 2:

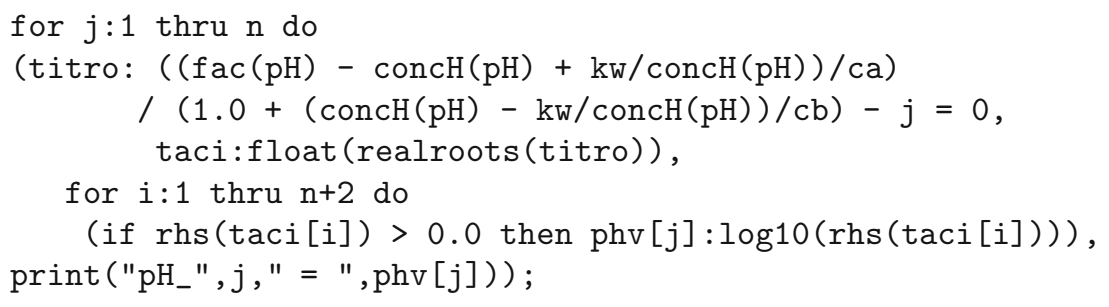


wxplot $2 d$ ([ [discrete, myx, myy], [discrete, myb, myy] ], [x, 0, n+1],

[y, 0,14], [style, [lines , 2,6] , [lines , 2, 2] ], [ylabel, "pH"] ,

[legend," "], [xlabel, "tau"], [legend," "]);

\section{Pure acid in water}

In the case of a monoprotic acid, from Eq. 11 one can obtain the acid concentration as a function of hydrogen ion concentration and $K_{a}$.

$$
C_{a}=\frac{\left[\mathrm{H}^{+}\right]^{2}}{K_{a}}-\frac{K_{w}}{K_{a}}+\left[\mathrm{H}^{+}\right]-\frac{K_{w}}{\left[\mathrm{H}^{+}\right]}
$$

Therefore, the $\log \left[C_{a}\right]$ can be plotted in function of the $\mathrm{pH}$ for selected values of $\mathrm{p} K_{a}$ obtaining a diagram similar to those introduced by Flood [16]. This is shown in Fig. 3.

The student can easily understand that also with a strong acid (for example, $\mathrm{p} K_{a}=0,1$ ) and a low acid concentration, the $\mathrm{pH}$ of the solution approaches 7 . This will avoid that a student could obtain $\mathrm{pH}=8$ from a $10^{-8} \mathrm{M} \mathrm{HCl}$ solution! Of course, Eq. 11 can also display the exact $\mathrm{pH}$ of the solution. The lines plotted in Fig. 3 are all below $\mathrm{pH}=$ 7 since they refer only to acids HA of various $p K_{a}$ values. We can see that at adequately high analytical concentrations $C_{a}$ of weak acid, there is a linear relation between $\left[\mathrm{H}^{+}\right]$and $C_{a}$. However, the $\mathrm{pH}$ increase for a weak acid is slower than for a strong acid.

The file with wxMaxima program code to get the graph shown in Fig. 3 is available in Online Resource 2.

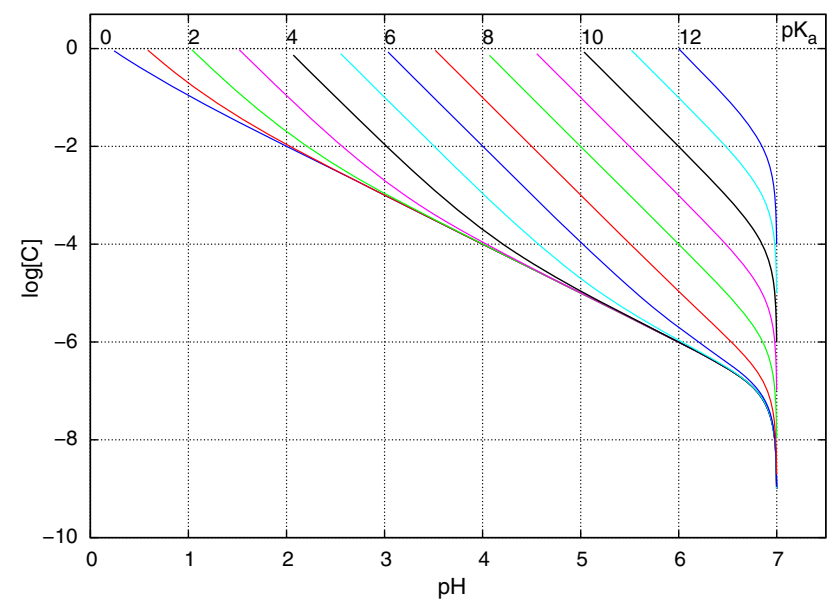

Fig. $3 \mathrm{pH}$ as a function of concentration for monoprotic acids of various strengths

\section{Conclusions}

The aim of this text is that students understand the formal calculation of acid-base equilibria with a simple and powerful method. These procedures will prepare them to handle similar systems later in their professional career. Often there appears to be considerable resistance on the part of instructors to use this kind of approach. The reasons given are that it emphasizes mathematics and not chemistry and that it uses computers also with relatively simple problems. In response, it can be argued that students learn precisely what part of chemistry is involved in acid-base equilibria and using computers and computer software is simply a matter of convenience to eliminate tedium for large-scale systems.

Nevertheless, a good knowledge of the construction of logarithmic diagrams handmade is a prerequisite to get acquainted with the computational approach.

The students certainly need to understand the algebraic approach to equilibrium so they can apply it in other situations such as the solubility of metal hydroxides, oxidehydroxides and oxides [17].

In addition, these diagrams could also be taken into account when redox equilibria are involved. This wide applicability of logarithmic diagrams has been recognized and their convenient construction as presented in this work should enhance their use to solve complex real problems.

\section{References}

1. Kovac J (2012) Using the logarithmic concentration diagram, $\log \mathrm{C}$, to teach acid-base equilibrium. J. Chem. Educ. 89:905-909

2. Kahlert H, Scholz F (2013) Acid-base diagrams. Springer, Berlin

3. Pavelle R (ed) (1985) Applications of computer algebra. Kluwer Academic Publishers, Boston

4. Roussel MR (1999) Redesigning the quantum mechanics curriculum to incorporate problem solving using a computer algebra system. J. Chem. Educ. 76:1373-1377

5. Matsumoto PS (2014) Exploring interactive and dynamic simulations using a computer algebra system in an advanced placement chemistry course. J. Chem. Educ. 91:1326-1333

6. Bhairav DJ (1996) Computer algebra systems as tools for chemical education. Chem Edu 1:1-14

7. Noggle JH (1996) Physical Chemistry. Pearson

8. http://wxmaxima.souceforge.net. Accessed March 2016

9. http://www.gnuplot.info. Accessed March 2016

10. http://maxima.souceforge.net. Accessed March 2016

11. http://maxima-online.org. Accessed March 2016 
12. Butler JN (1964) Ionic equilibrium: a mathematical approach. Addison-Wesley, Reading

13. Butler JN (1998) Ionic equilibrium, solubility and pH calculations. Wiley, New York

14. Freiser H, Fernando Q (1963) Ionic Equilibria in analytical chemistry. Wiley, New York

15. de Levie R (1993) Explicit expressions of the general form of the titration curve in terms of concentration. J. Chem. Educ. 70:209-217
16. Flood H (1940) Graphische orientierung über pH in säure-, baseund salzlösungen. Ztschr. Elektrochem. 46:669-675

17. Scholz F, Kahlert H (2015) The calculation of the solubility of metal hydroxydes, oxide-hydroxides, and oxides, and their visualization in logarithmic diagrams. Chem. Texts 1:1-9 